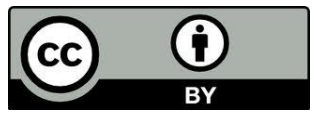

\title{
O currículo do Ensino Religioso e as matrizes culturais do povo brasileiro
}

\author{
The curriculum of religious education and cultural matrices of the Brazilian people
}

\begin{abstract}
Graduação em Pedagogia, habilitação em Orientação Educacional e Administração Escolar e Formação Teológica. Especialização em Administração Escolar; Ecumenismo e Diálogo Inter-religioso. Mestrado em Teologia Prática pela Escola Superior de Teologia - Instituto Ecumênico de Pós-Graduação de São Leopoldo - RS (1995). Doutorado em Educação: Currículo pela PUC-SP (2007). É membro do Grupo de Assessoria e Pesquisa Nacional de Ensino Religioso da Conferência Nacional dos Bispos do Brasil (GRAPER/CNBB). Docente Pesquisadora da Universidade do Planalto Catarinense UNIPLAC, no Programa de Pós-Graduação, Mestrado em Educação (PPGE) e integrante do Grupo de Pesquisa Educação e Formação de Professores. lurcaron@gmail.com.
\end{abstract}

RESUMO: O povo brasileiro está marcado pelo substrato das mais diferentes matrizes culturais e no currículo escolar estas matrizes necessitam estar contempladas, pois, a riqueza da cultura brasileira acompanha as populações em todos os seus movimentos. Para tanto, são necessárias efetivas políticas públicas de formação de professores, visto que a escola é uma instituição do saber que reproduz e recria significados culturais. Este estudo adota a metodologia da pesquisa histórico-bibliográfica e documental. Parte da problemática - como e quando na formação de professores de Ensino Religioso (ER) e na proposta curricular deste componente, surge a preocupação e reflexão com o tema Matrizes Culturais do povo brasileiro e o currículo de Ensino Religioso? Tem como objetivo aprofundar reflexão sobre diferentes matrizes culturais do povo brasileiro e o currículo de Ensino Religioso. A reflexão está respaldada em teóricos que dão suporte ao tema culturas e, em documentos e Relatórios de Encontros Nacionais de Ensino Religioso (ENERs); nos Parâmetros Curriculares Nacionais (PCNs) do Ministério da Educação e Cultura e nos Parâmetros Curriculares Nacionais do Ensino Religioso (PCNER). Os resultados apontam que a preocupação com as diferentes culturas está presente no ER a partir de década de 70, do século passado. No entanto, no currículo de ER, o tema sobre "diferentes matrizes culturais religiosas do povo brasileiro", toma corpo, a partir do $7^{\circ}$ ENER, 1988, e mais sensivelmente, a partir 1997, com os debates do Fórum Nacional Permanente de Ensino Religioso, nos Cursos de formação de professores e, principalmente, na elaboração dos PCNER, ao definir um dos eixos dos conteúdos "Culturas e Tradições Religiosas". Esta reflexão, poderá contribuir com a formação de professores para este componente curricular, bem como, para o respeito à liberdade religiosa e o exercício da cidadania.

Palavras-chave: Currículo de Ensino Religioso; Políticas Públicas; Formação de Professores

ABSTRACT: The Brazilian people is marked by the substrate from different cultural matrices and the school curriculum these matrices need to be addressed, for the richness of Brazilian culture accompanies populations in all his movements. Therefore, effective policies are needed teacher training, since the school is an institution of learning that reproduces and recreates cultural meanings. This study adopts the methodology of historical-bibliographical and documentary. Part of the problem - how and when the training of teachers of Religious Education (RE) and the curriculum of this component, there is a preoccupation with the theme and reflection matrices of the Brazilian Cultural and Religious Education curriculum? Aims to deepen reflection on different cultural matrices of the Brazilian people and the Religious Education curriculum. Reflection is backed by theorists that support the theme cultures, and documents and reports National Meetings of Religious Education (ENERs), the National Curriculum Parameters (PCN) of the Ministry of Education and Culture and the National Curriculum of Religious Education ( PCNER). The results indicate that concern about different cultures is present in the ER from the 70's of last century. However, the curriculum of ER, the theme of "different cultural matrices religious of the Brazilian people," takes shape, from the 7th ENER, 1988, and more significantly, from 1997, with discussions of the Permanent National Forum of Religious Education in teacher training courses, and especially in the preparation of PCNER, when defining an axis of contents "Cultures and Religious Traditions." This reflection may contribute to the training of teachers for this curricular component, as well as to respect religious freedom and citizenship.

Keywords: Curriculum Religious Education, Public Policy Teacher Education 


\section{Considerações iniciais}

A sociedade brasileira está profunda e predominantemente, marcada por um substrato religioso de matriz cultural cristã, trazido pelos primeiros colonizadores europeus e mantido, principalmente, até a década de 70, do século passado, pela tradição católica e pelas demais tradições religiosas, históricas cristãs.

A riqueza da cultura brasileira acompanha as populações em todos os seus movimentos. Em todos os tempos, houve e haverá o deslocamento de populações de seus lugares de origem para outros rincões do planeta. Este fato tem ensejado a formação de novas variedades físicas e culturais, a partir dos contatos que, necessariamente, se estabelecem numa nova situação. A população mantém vivo o movimento de buscar, de cultivar ou reacender suas tradições culturais, pois a cultura está localizada na mente, está no imaginário, está no coração das pessoas. Para Geertz (1989, p. 9), “A cultura é pública porque o significado também o é".

A palavra Cultura que vem do latim colere $=$ cultivar, etimologicamente parece simples, mas é de difícil conceituação e aplicabilidade, já que cada disciplina ou ciência a define sob o aspecto que considera importante e fundamental, segundo seu ponto de vista.

As diferentes matrizes culturais brasileiras, enriquecida pelas culturas indígenas, afrodescendentes e outras, trazidas para o Brasil ou criadas pela necessidade de sobrevivência, consideramos que influenciaram profundamente na maneira de ser e de viver do povo brasileiro. Neste sentido, “é a cultura o 'leitmotiv' da sua maneira de perceber-se, estar e agir no mundo" (FONAPER, Caderno Temático nº 2, 2000, p. 7).

Este estudo objetiva desenvolver reflexão sobre as diferentes matrizes culturais do povo brasileiro e o Currículo para Ensino Religioso, bem como, identificar ações que foram desenvolvidas em vista da formação de professores para o Ensino Religioso, que trataram do cultivo, do respeito, da reverência frente às diferentes culturas e tradições religiosas do nosso povo.

Nossa reflexão é respaldada em teóricos que dão suporte ao tema culturas e em documentos e relatórios de Encontros Nacionais de Ensino Religioso; os Parâmetros Curriculares Nacionais (PCNs) do Ministério da Educação e Cultura, que tratam da questão da Pluralidade cultural brasileira; dos Parâmetros Curriculares Nacionais do 
Ensino Religioso (PCNER), no eixo Culturas e tradições religiosas e Diversidade Religiosa.

Adotamos a metodologia da pesquisa histórico-bibliográfica e documental. Partimos da problemática - como e quando na formação de professores de Ensino Religioso e na proposta curricular deste componente, surge a preocupação e reflexão com o tema Matrizes Culturais do povo brasileiro e o currículo de Ensino Religioso?

Este artigo é parte de uma monografia de final de semestre, realizada em cumprimento às exigências do Programa de Pós-Graduação em Educação: Currículo, na disciplina: Currículo e cultura brasileira, durante o doutoramento na PUCSP. A monografia desenvolveu conteúdos de reflexões sobre Matrizes Culturais do povo brasileiro e o Currículo do Ensino Religioso. Este estudo até o presente não foi divulgado.

Como parte da monografia acima citada, é uma pesquisa inacabada. Aspectos históricos, antropológicos, filosóficos e sociológicos evidenciaram-se durante a elaboração deste trabalho. Há questões que, em nossa reflexão ficaram em aberto, e nesse tempo de "mudança de época" e de implementação de currículo de Ensino Religioso para a educação básica, merecem serem aprofundadas por pesquisadores interessados no tema.

Aprofundar reflexões e pesquisas acadêmicas relacionadas a cultura e o currículo de Ensino Religioso, certamente, ajudará na reconstrução da história de educação marcada pela cultura do povo brasileiro e nela, a influência no Ensino Religioso, principalmente, na educação básica. Isto, por acreditar que é possível fazer o diferente, marcar a diferença.

Na sequência, apresentamos reflexão acerca da Pluralidade Cultural Brasileira, nos Parâmetros Curriculares Nacionais.

\section{Pluralidade Cultural nos Parâmetros Curriculares Nacionais}

Os Parâmetros Curriculares Nacionais elaborados pelo Ministério da Educação e Cultura / Secretaria de Ensino Fundamental (MEC/SIF), em 1997, destacam que a pluralidade cultural diz respeito,

1 O Documento de Aparecida: Texto conclusivo da V Conferência Geral do Episcopado Latino Americano e do Caribe de 13-31 de maio de 2007, $\mathrm{n}^{\circ} 44$, reflete que, vivemos uma mudança de época, e seu nível mais profundo é o cultural. 


\begin{abstract}
Ao conhecimento e à valorização das características étnicas e culturais dos diferentes grupos sociais que convivem no território nacional, às desigualdades socioeconômicas e à crítica às relações sociais discriminatórias e excludentes que permeiam a sociedade brasileira, oferecendo ao aluno a possibilidade de conhecer o Brasil como um país complexo, multifacetado e algumas vezes paradoxal (PCNs, (10), 1997, p.19).
\end{abstract}

Ao se tratar sobre a pluralidade cultural brasileira, é preciso respeitar e valorizar as diferenças étnicas e culturais, porém, isto, não significa "aderir aos valores do outro, mas, sim, respeitá-los como expressão da diversidade, respeito que é, em si, devido a todo o ser humano, por sua dignidade extrínseca, sem qualquer descriminação" (PCNs (v.10), 1997, p. 19-20).

As culturas são produzidas pelos grupos sociais ao longo das suas histórias, na construção de suas formas de subsistência e na sua organização. Nas relações do ser humano com o meio em que vive, com outros grupos e na produção de conhecimentos, está presente a cultura e a política.

A diferença entre culturas é resultado das singularidades dos processos em cada grupo social e o "grande desafio proposto para a educação é estabelecer conexões entre o que se aprende na escola e a vida da população brasileira“ (PCNs (10), 1997, p. 23).

A escola como espaço de construção e socialização de conhecimentos, por sua natureza, tem uma dupla função: trabalhar com os conhecimentos humanos sistematizados, historicamente produzidos e acumulados e criar novos conhecimentos. E, como todo conhecimento humano é sempre patrimônio da humanidade, o conhecimento religioso precisa estar disponível a todos aqueles e aquelas que a ele queiram ter acesso (PCNER. 1997, 2123). Conhecimento novo, que conforme Paulo Freire (2002, p. 31), ao ser produzido, "supera outro que antes foi novo e se fez velho e se 'dispõe' a ser ultrapassado por outro amanhã. Daí que seja tão fundamental conhecer o conhecimento existente quanto saber que estamos abertos e aptos à produção do conhecimento ainda não existente".

Conhecer significa captar e expressar as dimensões da comunidade de forma cada vez mais ampla e integral. Por isso à escola compete integrar, dentro de uma visão de totalidade, os vários níveis de conhecimento: o sensorial, o intuitivo, o afetivo, o racional e o religioso. O conhecimento religioso, enquanto sistematização de uma das dimensões de relação do ser humano com a realidade transcendental está ao lado de outros que, articulados, explicam o significado da existência humana. 
À escola compete prover os educandos de oportunidades de se tornarem capazes de entender os momentos específicos das diversas culturas, cujo substrato religioso colabora no aprofundamento para autêntica cidadania. E, como nenhum conhecimento teórico sozinho explica completamente o processo humano, é o diálogo entre eles que possibilita construir explicações e referenciais, que escapam do uso ideológico, doutrinal ou catequético. Pois, "o diálogo é o encontro dos seres humanos mediatizados pelo mundo, para pronunciá-lo, não se esgotando, a relação eu-tu”. E só existe o diálogo, quando há profundo amor e respeito ao mundo e ao ser humano (FREIRE, 1980, p. 92-93).

Neste sentido, segundo os Parâmetros Curriculares Nacionais do Ensino Religioso - PCNER, na escola, este componente curricular tem a função de garantir a todos os educandos a possibilidade de estabelecerem diálogo com o diferente, com as diferentes culturas e tradições religiosas. E, como o conhecimento religioso está no substrato cultural, este ensino contribui para a vida coletiva dos educandos, na perspectiva unificadora que a expressão religiosa tem, de modo próprio e diverso, diante dos desafios e conflitos.

Conforme os PCNER, o conhecimento resulta das respostas oferecidas às perguntas que o ser humano faz a si mesmo e ao informante. Às vezes para fugir à insegurança, resgatando sua liberdade, ele prefere respostas prontas, que apaziguam a sua ansiedade. A raiz do fenômeno religioso encontra-se no limiar dessa liberdade e dessa insegurança.

Os PCNs (1997, p. 28), refletem de que "a pluralidade cultural existente no Brasil é resultado de um longo processo histórico de interação entre aspectos políticos e econômicos, no plano nacional e internacional”. A escola está marcada por prática cultural e historicamente arraigada, bem como, por "teorias que deslocaram a responsabilidade da escola para o aluno, além de currículos e formação de professores insuficientes" (PCNs (10), 1997, p. 33).

A equipe de elaboração dos PCNs, no Ministério da Educação, demonstrou certa reserva com relação ao Ensino Religioso e ao mesmo tempo, retratou uma concepção deste ensino na compreensão de religião, sem, no entanto, explicitar o que entende por religião e muito menos, por Ensino Religioso. Para não dizer que não falou deste ensino, registra a seguinte preocupação: 
O Ensino Religioso nas escolas públicas é assunto que exige atenção. Tema vinculado, em termos de direito, à liberdade de consciência e de crença, a presença plural das religiões no Brasil constitui-se fator de possibilidade de escolha. Ao indivíduo é dado o direito de ter religião, quando criança, por decisão de seus pais, ou, quando adulto, por escolha pessoal; de mudar de religião, por determinação voluntária ao longo da vida, sem restrição de ordem civil; e de não ter religião, como opção consciente. O que caracteriza, portanto, a inserção social do cidadão, desse ponto de vista, é o respeito, a abertura e a liberdade (PCNs (10), 1997, p. 38).

O direito à liberdade de consciência e de crença faz parte do conjunto dos direitos de todo o cidadão, de toda a cidadã. Para que na educação seja respeitado o diálogo com as diferentes culturas é de suma importância que, em nível nacional, Instituições de Ensino Superior viabilizem cursos de formação de professores incluindo também os de Ensino Religioso.

Convêm, no entanto, considerar, que a partir da Lei $n^{\circ} 9.475 / 97$, a política de capacitação, efetivação e habilitação de professores para o Ensino Religioso no Brasil, assim como o respeito à diversidade cultural religiosa brasileira estão se constituindo em objeto de interesse de Instituições de Ensino Superior e de diferentes setores da sociedade brasileira, mesmo que em trabalho mais lento.

No Brasil, o fio condutor de toda e qualquer iniciativa que visa organizar e efetivar o Ensino Religioso como disciplina do currículo é o princípio da liberdade religiosa. Este, por sua vez, é regido pelo princípio da laicidade que configura a própria natureza de um estado republicano e as instituições pelo mesmo, gerenciadas.

Destaca-se que, a partir da década de 80, e mais especificamente, nos anos 90 do século passado, uma das questões temáticas a envolver a reforma educativa brasileira, abordava a pluralidade cultural religiosa presente nas escolas brasileiras e, em consequência da mesma, a necessidade de uma proposta de Ensino Religioso, capaz de integrar em seus conteúdos e política pedagógica, esse referencial, onde o acesso ao conhecimento religioso sistematizado historicamente pela humanidade é assegurado a todo cidadão, a toda a cidadã.

Esta preocupação com a pluralidade cultural religiosa do povo brasileiro, na medida em que professores começaram a refletir sobre questões ligadas ao Ensino Religioso, passa, cada vez mais, a fazer parte das reflexões, cursos e encontros.

A Lei $n^{\circ}$ 9.457, de 22 de julho de 1997, deu nova redação ao art. 33 da Lei $n^{\circ}$ 9.394, de 20 de dezembro de 1996, e estabeleceu as diretrizes e bases da educação nacional, garantindo o Ensino Religioso como uma disciplina integrante do sistema 
escolar, considerada como elemento essencial para a formação do cidadão; faculta a matrícula para o aluno, segundo os princípios da liberdade religiosa; exige o respeito à diversidade cultural-religiosa do Brasil e veda quaisquer formas de proselitismo ${ }^{2}$.

A Conferência Nacional dos Bispos do Brasil (CNBB), consciente do papel social da educação no seu sentido mais amplo, preocupada com a formação de professores para o Ensino Religioso, iniciou, em 1974, a promover e realizar Encontros Nacionais para Coordenadores e Professores de Ensino Religioso, nos Estados (ENER).

A questão da pluralidade cultural ou do fenômeno religioso no contexto da matriz cultural do povo brasileiro esteve presente nas reflexões sobre Ensino Religioso e nas ações, visando a formação de professores, mais especificamente a partir do acompanhamento e debates no período da Assembleia Constituinte, 1985-1988, e, posteriormente, na Constituição de 1988, na elaboração da Lei de Diretrizes e Bases da Educação (LDB) Lei n 9.394/96. Também se fez presente nos Encontros Nacionais de Ensino Religioso (ENERs), realizados entre 1988-1998 do século passado, em cursos de formação de professores de ER. Nos cursos de formação para ER, o tema das diferentes culturas, recebeu maior ênfase. Assim, na sequência destacamos sínteses de Encontros em que o tema Cultura e fenômeno religioso tenha sido objeto de reflexão, atenção e pesquisa.

\section{Encontros Nacionais de Ensino Religioso}

Os Encontros Nacionais de Ensino Religioso - $(\text { ENER })^{3}$ tem sido o grande impulsionador para a caminhada deste ensino, para a definição e organização curricular, atendendo aspectos quanto: ao objeto de estudo, o objetivo, o conteúdo, a metodologia didática-avaliativa, a linguagem, a história, o espaço cultural, conquistando cada vez mais o seu espaço como componente integrado às ações pedagógicas, disciplina escolar, direito do cidadão.

\footnotetext{
${ }^{2}$ Este assunto é tratado em CARON, Lurdes (org.) e equipe do GRERE. Ensino Religioso na nova LDB, 1997, p. 31-41.

${ }^{3}$ Estes Encontros eram promovidos pela CNBB, e realizados de dois em dois anos. Durante a Assembleia Constituinte, a promoção dos mesmos, foi anual. Posterior a 1988, a CNBB, continuou promovendo estes encontros, novamente de dois em dois anos, até 1998. A partir de 1996 - 1997, FONAPER, assumiu a parte política e pedagógica do ER. A CNBB passou então, a preocupar-se mais com a formação de professores de ER, das escolas católicas.
} 
As reflexões e estudos provocados a partir dos Encontros Nacionais e as constantes mudanças sociopolíticas, econômicas, culturais - religiosas, desafiaram as entidades envolvidas com este componente curricular e acima de tudo, os professores. A formação de professores foi uma tônica constante em todos os ENERs. O Ensino Religioso no respeito à pluralidade cultural religiosa do povo brasileiro, é objeto de reflexão mais acentuadamente, a partir do $7^{\circ}$ ENER realizado em Brasília/DF, em 1988. Os ENERs posteriores, todos, com diferentes enfoques, trataram da pluralidade cultural religiosa do povo brasileiro.

Do $7^{\circ}$ Encontro Nacional de Ensino Religioso $\left(E N E R^{4}\right)$, resultou uma carta aberta aos educadores, na qual é definido o posicionamento dos participantes. Consta no Relatório,

\begin{abstract}
Defendemos a escola pública, gratuita e de qualidade e a implantação de um plano de carreira para o professor de ER. O Ensino Religioso, como educação da dimensão religiosa da pessoa humana, respeitado o pluralismo cultural, de ideias, de concepções pedagógicas e da liberdade religiosa, portanto, faz parte do processo global e integral da educação. O Ensino Religioso na escola contribui para que ela possa situar-se a partir da realidade do educando, levando em consideração sua vida e sua cultura. Nosso esforço é contribuir, a partir da dimensão religiosa, para a transformação da sociedade dividida em classes sociais, numa perspectiva libertadora, em uma sociedade justa, fraterna, humana e solidária (CNBB, 1994-1998, $7^{\circ}$ ENER).
\end{abstract}

O $8^{o}$ Encontro Nacional de Ensino Religioso, realizado em 1990, em Petrópolis/RJ, se propôs a continuar a reflexão sobre os desafios da realidade cultural e das novas leis de ensino e ao mesmo tempo, buscar pistas metodológicas, tendo como fio condutor o marco antropológico na prática pedagógica renovada. O tema principal foi o Ensino Religioso e a dimensão metodológica com enfoques no marco antropológico, na prática pedagógica, com destaque: a linguagem, interdisciplinaridade e sobre o processo histórico da educação nos últimos anos.

O $9^{\circ}$ Encontro Nacional de Ensino Religioso, realizado em São Paulo, Instituto Salesiano Pio XI, em agosto de 1992, da continuidade às reflexões do $7^{\circ}$ e $8^{\circ}$ ENER. Este encontro teve como objetivo a reflexão sobre a identidade, conteúdos e linguagem do Ensino Religioso, tendo em vista a compreensão do seu papel numa educação e

\footnotetext{
${ }^{4}$ As sínteses apresentadas aqui, são retiradas do Caderno de Estudos elaborado por CARON (1999, p. 15 - 16), e dos Relatórios dos Encontros Nacionais de Ensino Religioso, promovidos pela CNBB (19741998), In: arquivo da CNBB - Setor de Ensino Religioso. Brasília, 1998.
} 
prática interdisciplinar que favoreça a formação integral e integradora de educando e educador.

O $10^{\circ}$ Encontro Nacional de Ensino Religioso - foi realizado em Fortaleza Ceará, em 1994. Teve como temas centrais: Mudanças socioculturais e o fenômeno religioso; Manifestações religiosas e o diálogo inter-religioso; Prática da Interdisciplinaridade: operacionalização. Esse ENER destacou aspectos pertinentes ao Ensino Religioso, tais como: compreensão do ER, tendência do sincretismo religioso no mundo cultural pluralista e crescimento dos Novos Movimentos Religiosos, o progresso técnico científico e como articular e inserir tais aspectos na educação para o equilíbrio harmônico entre a imanência e a transcendência. Destacou que a pessoa humana é o centro do fazer Ensino Religioso, não podendo, no entanto, ficar ausentes as perspectivas da ética.

O $11^{\circ}$ Encontro Nacional de Ensino Religioso teve como ponto referencial de partida as seguintes hipóteses: a complexidade cultural do povo brasileiro constituindose, ao mesmo tempo, em riquezas e desafios os quais necessitam serem considerados no tratamento didático do ER. As diferentes matrizes da cultura do povo brasileiro apresentam também, diferentes experiências religiosas. Este contexto aponta um novo paradigma que exige permanente mudança de linguagem e prática de diálogo e respeito permeando o conteúdo pedagógico para o ER. Ainda, a contribuição das diferentes culturas na educação brasileira é referencial determinante no fazer pedagógico e o currículo escolar para o ER.

O tema desenvolvido no $11^{\circ}$ ENER foi "O Impacto entre a matriz sóciopolítico-econômico-cultural e religiosa e as culturas advenientes (3 Milênio)”. Este evento objetivou: Conhecer a realidade, destacando princípios e critérios que possam nortear a ação do Ensino Religioso no Brasil.

O trabalho desenvolveu-se da seguinte forma: 1) As coordenações de Ensino Religioso (existentes na época), em cada Estado realizaram estudos sobre o assunto com os seus professores. 2) Os estudos, análise e levantamento de princípios e critérios para o ER, foram norteados a partir das seguintes questões: Apresentar aspectos sóciopolítico-econômico-culturais e religiosos presentes em cada Estado, destacando nesses, alguns impactos; Apontar princípios e critérios que possam nortear a ação pedagógica do Ensino Religioso tendo em vista: um ser humano como protagonista da história; uma 
educação para o pleno exercício da cidadania; uma sociedade pluralista, justa e solidária.

Frente à realidade constatada, os princípios e critérios levantados a partir da prática do Ensino Religioso em cada Estado e diante da proposta curricular existente, solicitou-se a cada coordenação do ER nos estados 5 , trazer de forma sistematizada os itens: O que continua válido? O que é urgente implementar? O que se pretendia alcançar até o ano 2000? Quais as metas intermediárias para cada etapa? Quais os recursos humanos e financeiros disponíveis?

Para responder às perguntas, os(as) representantes das Coordenações de ER trouxeram sintetizadas as discussões dos estudos (em uma lauda de, no máximo, 25 linhas para cada pergunta). Estas foram apresentadas no plenário, durante a realização do ENER.

Durante e a partir deste $11^{\circ}$ ENER, os participantes, sentiram-se desafiados a definir Linhas de Ação, comuns, para o ER no Brasil. Encerrado este Encontro, na sequência, realizou-se, em Brasília - DF, a $1^{\text {a }}$ Sessão do Fórum Nacional de Reflexão Permanente do Ensino Religioso (FONAPER). Este, a partir desta sessão, assumiu e coordenou em nível nacional a elaboração dos Parâmetros Curriculares Nacionais para o Ensino Religioso no Brasil (PCNER).

Parâmetros Curriculares do Ensino Religioso: marco histórico na educação brasileira

Em se tratando de Cultura e Educação, a partir da elaboração dos Parâmetros Curriculares Nacionais pelo MEC e tendo em vista a não inclusão do Ensino Religioso nos mesmos, o Fórum Nacional de Reflexão Permanente, (FONAPER) ${ }^{6}$, cujos associados, na sua maioria, são professores, em articulação com o Setor de Ensino Religioso da Conferência Nacional dos Bispos do Brasil da (CNBB) e o Grupo de

\footnotetext{
${ }^{5} \mathrm{Na}$ década de 90 do século passado era comum a figura do Coordenador de Ensino Religioso junto à equipe pedagógica da Secretaria de Estado da Educação ou então, nas Dioceses da igreja Católica Apostólica Romana (ICAR).

${ }^{6}$ O Fórum Nacional de Reflexão Permanente do Ensino Religioso (FONAPER), é instalado em 26 de setembro de 1995, em Florianópolis, por ocasião dos 25 anos da $1^{a}$ experiência de Educação Religiosa Escolar, uma proposta aberta a todo o educando, para as escolas públicas de SC, e ao mesmo tempo, os 25 anos do Conselho de Igrejas para Educação Religiosa Escolar (CIER).
} 
Reflexão sobre Ensino Religioso (GRERE) ${ }^{7}$ e outras entidades afins, mobilizaram-se para a inclusão do Ensino Religioso nos Parâmetros Curriculares Nacionais (PCNs).

Elaborou e divulgou a partir de 1996-1997, os Parâmetros Curriculares Nacionais do Ensino Religioso (PCNER), que subsidiaram os debates e encaminhamentos das propostas de lei para o Ensino Religioso na elaboração da nova LDBEN promulgada em 20/12/96, assim como a subsequente alteração de redação do artigo 33, originando a Lei n 9475 de Julho de 1997 (JUNQUEIRA, 2002, p. 70-77).

Como um dos resultados de estudos e reflexões coletivas, a partir do ano de 1996 - 1997, os Parâmetros Curriculares Nacionais de Ensino Religioso (PCNER), foram elaborados e aprovados pelo Plenário do Fórum Nacional Permanente de Ensino Religioso (FONAPER) ${ }^{8}$, na sua terceira sessão em Piracicaba, cidade do Estado de São Paulo, no mês de março do ano de 1997.

Esse documento apresenta os referenciais para um Ensino Religioso que, valorizando o pluralismo e a diversidade cultural presentes na sociedade brasileira, facilitam a compreensão das formas que exprimem o Transcendente na superação da finitude humana e que determinam subjacentemente, o processo histórico da humanidade; (...) por isso não pode ser entendido como Ensino de uma Religião ou das Religiões na Escola, mas sim uma disciplina centrada na antropologia religiosa (FONAPER, 1997, p. 11 e 30).

Este fato acontece, no entendimento de que a "escola é o espaço de construção de conhecimentos, mas principalmente, de socialização dos conhecimentos historicamente produzidos e acumulados" (SAVIANI, 1991, p. 22, 24). E em relação à raiz do fenômeno religioso, é necessário ter presente que se fundamenta na finitude do ser humano que "descobre que pouco sabe de si, de seu 'posto no cosmos', e se inquieta por saber mais. (...) Como incluso, busca fora de si, de sua competicidade, e com isso transcende-se a si mesmo" (FREIRE, 1980, p. 29-30).

\footnotetext{
7 O GRERE, criado em 1985, é constituído por professores especialistas do Ensino Religioso. Presta assessoria ao Setor de Ensino Religioso da CNBB, quanto a elaboração de documentos, análise e reflexões sobre o assunto.

${ }^{8}$ O FONAPER é "uma sociedade civil de âmbito nacional, sem vínculo político-partidário, confessional e sindical, sem fins lucrativos, sem prazo determinado de duração, que congrega, conforme este Estatuto, pessoas jurídicas e pessoas físicas identificadas com o Ensino Religioso Escolar e se constitui em um organismo que trata questões pertinentes ao Ensino Religioso - ER, sem discriminação de qualquer natureza." FONAPER, Estatuto, cap. I, art. 1.
} 
Os Parâmetros Curriculares Nacionais do Ensino Religioso constituem-se, sem dúvida, num marco histórico da educação brasileira. Pela primeira vez, na história do Ensino Religioso no Brasil, pessoas de várias tradições religiosas, educadores, conseguiram juntas construir os elementos constitutivos para o Ensino Religioso, como disciplina escolar. Este ensino, ao longo da história, no Brasil, tem sido caracterizado pelo binômio: Ensino da Religião, Ensino Religioso, na maioria das vezes, entendido politicamente, como uma concessão ${ }^{9}$ do Estado às igrejas e vice versa. A compreensão e metodologia deste ensino passam por mudanças de paradigma. Neste sentido, o FONAPER, passou a preocupar-se prioritariamente com a formação de professores para o Ensino Religioso.

\begin{abstract}
A mudança de paradigma na concepção do Ensino Religioso, a elaboração dos PCNER e a busca de definição de Diretrizes Curriculares Nacionais para a formação de professores para esta área do conhecimento, junto ao Ministério da Educação e Cultura passaram a exigir novas propostas de formação docente para esta área do conhecimento (JUNQUEIRA, 2002, p. 98-99).
\end{abstract}

A reflexão de Junqueira sobre novos paradigmas no Ensino Religioso também está ligada à definição de que o objeto deste componente curricular é o fenômeno religioso na compreensão da busca do "Ser frente à ameaça do Não ser". Nesta busca de sentido, a humanidade formula "quatro respostas possíveis como norteadoras do sentido da vida além morte: A Ressurreição, a Reencarnação, o Ancestral e o Nada" (Cf. PCNER, 1997, p. 32).

E assim, cada uma dessas respostas organiza-se num pensamento próprio, obedecendo a uma estrutura comum. É dessa estrutura comum que são retirados os critérios para organização e seleção dos conteúdos e objetivos do Ensino Religioso. Assim, na pluralidade da escola brasileira, esses critérios para os blocos de conteúdos em Ensino Religioso, estão organizados em cinco eixos fundamentais: Culturas $e$ Tradições Religiosas, Escrituras Sagradas elou Tradições Orais, Teologias, Ritos e Ethos. (Cf. PCNER, 1997, p. 32 - 33).

Para a dinamização dos Parâmetros Curriculares Nacionais do Ensino Religioso (PCNER), a necessidade primordial é a da formação de professores. A formação inicial e continuada de professores para o Ensino Religioso é uma exigência para a qual é

\footnotetext{
${ }^{9}$ A questão de concessão é trabalhada na obra de CARON, Entre Conquistas e Concessões: uma experiência ecumênica em educação religiosa escolar. São Leopoldo, RS: Sinodal, 1997.
} 
preciso que se afirme e confirme políticas públicas para a contínua formação de professores para que transpareça, em suas práticas pedagógicas o respeito às diferentes manifestações culturais e religiosas do povo brasileiro e os direitos humanos. A partir dos PCNER, neste trabalho, destacaremos somente o eixo Culturas e tradições religiosas.

\section{Culturas e Tradições Religiosas}

Falar de cultura, tradição e religião significa falar de elementos que se conectam, ou seja, que se co-implicam, pois estão em contínua relação. Para Dussel (1975, p. 73),

\footnotetext{
Cultura, culto e religião, enquanto formas de um complexo sistema simbólico, implica aproximação do outro, junto com outros, em adoração ao outro-transcendente - este núcleo "ético mítico" - de uma cultura" (...). No pensamento mítico, o espaço e o tempo nunca são considerados como formas puras ou vazias. São vistos como as grandes forças misteriosas que governam todas as coisas, que regem e determinam não só a nossa vida mortal, mas também a vida dos deuses.
}

Toda a cultura tem o seu `núcleo ético-mítico`, que possibilitam ao ser humano gerar um complexo de posturas e comportamentos existenciais práticos. Na reflexão de Dussel (1975), toda cultura, tem em si, um sentido religioso.

O Caderno Temático 2, elaborado pelo FONAPER, para ajudar os professores na reflexão sobre Tradições e culturas religiosas, tem como conteúdo, Ensino Religioso: culturas e tradições religiosas, fala de que "As teorias que consideram a cultura como um sistema adaptativo foram fortemente difundidas por teóricos neo-evolucionistas e que apesar das divergências, entende que "Culturas" são sistemas (padrões de comportamento socialmente transmitidos) que serve para adaptar as comunidades humanas aos seus embasamentos biológicos. "Esse modo de vida das comunidades inclui tecnologias e modos de organização econômica, padrões de estabelecimento, de agrupamento social e de organização política, de crenças e de práticas religiosa, e assim por diante" (Cf. FONAPER, 2, 2001, p. 8).

Por Culturas e tradições religiosas, os PCNER (1997, p. 33), definem que é o “estudo do fenômeno religioso à luz da razão humana, analisando questões como: função e valores da tradição religiosa, relação entre tradição religiosa e ética, teodiceia, tradição religiosa natural e revelada, existência e destino do ser humano nas diferentes culturas". 
Esse estudo reúne o conjunto de conhecimentos ligados ao fenômeno religioso em um número reduzido de princípios que lhe servem de fundamento e lhe delimita o âmbito da compreensão. Assim, "não se separa das ciências que se ocupam com o mesmo objeto como: filosofia da tradição religiosa, história e tradição religiosa, sociologia e tradição religiosa, psicologia e tradição religiosa, nem delimita, de maneira absoluta e definitiva, um critério epistemológico unívoco" (FONAPER, 1997, p. 33).

Tendo presente, a diversidade cultural religiosa do povo brasileiro, nos Parâmetros Curriculares Nacionais do Ensino Religioso, os conteúdos estabelecidos pelo FONAPER, no eixo- Culturas e Tradições Religiosas, compreendem: Filosofia da tradição religiosa: a ideia do Transcendente, na visão tradicional e atual; História e tradição religiosa: a evolução da estrutura religiosa nas organizações humanas no decorrer dos tempos; Sociologia e tradição religiosa: a função política das ideologias religiosas; Psicologia e tradição religiosa: as determinações da tradição religiosa na construção mental do inconsciente pessoal e coletivo (FONAPER, 1996, p. 35 - 36).

$\mathrm{Na}$ visão de Ensino Religioso de caráter mais aberto, compreendendo as diferentes culturas religiosas, $\operatorname{Azzi}^{10}(1996$, p. 09-10), afirma que,

\begin{abstract}
O ensino religioso, de caráter mais aberto e pluralista deva basear-se numa antropologia que considere o humano como ser paradoxal plenamente inserido no mundo natural, e, ao mesmo tempo, dotado de uma força espiritual que o leve a ultrapassa-la, em busca da transcendência. $O$ sentido de sacralidade do mundo e do ministério divino, revelado pelos textos religiosos, deve harmonizar-se com a celebração festiva da dança e do agradecimento expressivo pelo dom da vida.
\end{abstract}

Toda a cultura traz no seu bojo mitos, símbolos e suas festas. Ortiz (2003, p. 4344), ao falar sobre cultura brasileira e identidade nacional, a partir da miscigenação das três raças, diz que "O mito das três raças (negra, indígena e branca) ao se difundir na sociedade, permite aos indivíduos, das diferentes classes sociais e dos diversos grupos de cor, interpretar, dentro do padrão proposto, as relações raciais que eles próprios vivenciam”. Tem-se insistido muito sobre a dificuldade de se definir o que é o negro no Brasil. O impasse não é simplesmente teórico; reflete as ambiguidades da própria sociedade brasileira. "A construção de uma identidade nacional mestiça deixa ainda mais difícil o discernimento entre as fronteiras de cor" (p. 43). O autor afirma ainda, que

10 AZZI, Riolando. Doutor em Filosofia, professor na universidade Federal do Rio de Janeiro e pesquisador do Centro João XXIII - Rio de Janeiro. 
o mito das três raças "não somente encobre os conflitos raciais como possibilita a todo de se reconhecerem como nacionais" (ORTIZ, 2003, p. 44).

O FONAPER, consciente do respeito à diversidade cultural religiosa do povo brasileiro, e nela, o respeito aos Símbolos, Ritos e Mitos de cada cultura, incluiu nos PCNER este assunto, pois, ritos, com seus mitos, não podem estar desassociados da cultura. Os conteúdos são estabelecidos a partir de,

Rituais: a descrição de práticas religiosas significantes, elaboradas pelos diferentes grupos religiosos; Símbolos: a identificação dos símbolos mais importantes de cada tradição religiosa, comparando seu(s) significado(s); Espiritualidades: o estudo dos métodos utilizados pelas diferentes tradições religiosas no relacionamento com o transcendente, consigo mesmo, com os outros e o mundo (PCNER, 1997, p. 35).

Cada cultura independentemente de sua raiz, de sua tradição religiosa, do contexto social em que vive, elabora, cria para si na coletividade ou na individualidade formas de manifestar, de expressar, de viver sua espiritualidade e de cultivar seus símbolos e seus mitos. Geertz (1989), em sua obra: A interpretação das culturas, diz que,

Como sistemas entrelaçados de signos, interpretáveis [...], a cultura não é um poder, algo ao qual podem ser atribuídos casualmente os acontecimentos sociais, os comportamentos, as instituições ou os processos" e sim, ela faz parte do contexto social. E ainda, para o mesmo autor, "No estudo da cultura, os significantes não são sintomas ou conjuntos de sintomas, mas atos simbólicos ou conjuntos de atos simbólicos e o objetivo não é terapia, mas análise do discurso social (GEERTZ, Clifford, 1989, p. 18).

Com a reflexão de Geertz e no respeito ao pluralismo cultural religioso da sociedade brasileira, os conteúdos do Ensino Religioso, não podem servir ao proselitismo, mas sim proporcionar o conhecimento dos elementos básicos que compõem o fenômeno religioso. Com esses pressupostos, o tratamento didático dos conteúdos realiza-se em nível de análise e conhecimento, na pluralidade cultural da sala de aula, salvaguardando-se a liberdade da expressão religiosa do educando.

Assim, entende-se que o tratamento didático subsidia o conhecimento. E o Ensino Religioso, pelos eixos de conteúdos: Culturas e Tradições Religiosas, Escrituras Sagradas e/ou Tradições Orais, Teologias, Ritos e Ethos cada vez mais, vai 
sensibilizando para o mistério, capacitando para a leitura da linguagem mítico-simbólica e diagnosticando a passagem do psicossocial para a metafísica/Transcendente (Cf. PCNER, 38 - 39). Este tratamento didático dos conteúdos do Ensino Religioso prevê, como nas outras disciplinas, a organização social das atividades, organização do espaço e do tempo, seleção e critérios de uso de materiais e recursos.

De nada adianta falar em tratamento didático, ter Parâmetros Curriculares Nacionais de Ensino Religioso, sem atender ao desafio da formação de professores. Para isto, em caráter emergencial, o FONAPER, a partir de 1996, organizou e viabilizou Seminários de Capacitação Docente, e entre os anos de 2000-2002, o Curso de Formação de professores para o Ensino Religioso - 120 horas, na modalidade de Educação a distância. Este fato merece uma pesquisa acadêmica mais aprofundada. Convém ressaltar que estas ações práticas motivaram e abriram caminhos para, cada vez mais no currículo do Ensino Religioso e no geral da escola conhecer e respeitar as diferentes matrizes culturais de educandos e educadores. Deixamos esta temática em aberto como um convite para futuros pesquisadores.

\section{Considerações finais}

Cada cultura tem na sua estruturação, o seu substrato religioso que a caracteriza e a unifica, na vida coletiva, diante dos desafios e conflitos. Em cada indivíduo, em cada povo, em cada cultura, em cada espaço social, existe algo que é relevante para os demais, por mais diferentes que sejam entre si.

A pluralidade cultural religiosa, do povo brasileiro é um fato. E necessita fazer parte do currículo de formação, quer seja no contexto escolar ou fora do ambiente da escola. Para a educação neste contexto de respeito ao diferente e com as diferentes culturas, é necessário o diálogo não só no Ensino Religioso, mas em todo o processo educativo, onde quer que aconteça. E neste processo, o respeito às culturas, com seus Mitos, Ritos e símbolos, é imprescindível.

A nova proposta para o Ensino Religioso, a partir da Lei de Diretrizes e Bases da Educação Nacional, no artigo 33, com a redação da Lei no 9 475/97, aponta para um trabalho que seja alicerçado na inclusão, no respeito, na tolerância. A sala de aula, enquanto espaço para a aquisição de conhecimento, é também um lugar adequado para o exercício do respeito às diferentes culturas e às diferentes tradições religiosas. 
A educação no seu processo de formação teórico-prática necessita incorporar no currículo a pluralidade cultural brasileira e intercultural, sendo que esta última acontece mais pela convivência com o outro do que por teorias. Embora, na compreensão conceitual, cultura, escola e aprendizagem sejam diferentes, o currículo escolar necessita incorporar, articular e promover a aquisição de conhecimentos, de saberes, sem descuidar do respeito ao pluralismo cultural brasileiro.

Na história do Ensino Religioso no Brasil, nem sempre a pluralidade cultural religiosa foi respeitada nos conteúdos desta disciplina, principalmente até os anos 70 . Talvez possamos dizer que tenha sido mais tolerada. No entanto, como tudo evolui, registra-se que, mais especialmente, a partir dos anos 70-80, do século passado, e intensifica-se nos anos 90, o respeito à diversidade cultural brasileira começa e faz parte dos conteúdos de formação de professores para a docência com o Ensino Religioso e dos alunos. A partir de 1997, é parte do Currículo desta disciplina e está trabalhada nos Parâmetros Curriculares Nacionais do Ensino Religioso.

A preocupação e o assumir mais consciente de professores com as diferentes matrizes culturais religiosa do povo brasileiro, evidencia-se nos Encontros Nacionais de Ensino Religioso, mais sensivelmente a partir do $7^{\circ}$ ENER (1988), nos debates do Fórum Nacional de Reflexão Permanente de Ensino Religioso, nas suas Sessões e, principalmente, na elaboração dos PCNER, ao definir um dos eixos dos conteúdos Culturas e Tradições Religiosas posteriores, nos Cursos de formação de professores, nas produções de material didático para subsidiar o desempenho do professor na sua prática pedagógica, e hoje nas produções científicas.

Encerrando, o Ensino Religioso não é o único componente curricular responsável por mudanças sociais, religiosas, educacionais, e sim, todo o contexto educacional, com seu currículo "revelado" e mesmo o "oculto", é responsável para fazer e marcar a diferença, incorporando, dinamizando o conhecimento, o respeito à pluralidade cultural do povo brasileiro. E para isto, é indispensável a contínua formação de professores.

Assim, por último, registra-se que o presente trabalho oferece várias vertentes para continuar a reflexão, a partir da visão de diferentes autores, permanecendo a espera de aprofundamento. Como afirmamos anteriormente, este não é um trabalho acabado, é sim uma reflexão desenvolvida a partir de teorias e da prática profissional com a 
formação de professores para função de docência e com o Ensino Religioso. Questões ligadas à pluralidade cultural do povo brasileiro, envolvendo o currículo do Ensino Religioso, que aqui não são aprofundadas, poderão merecer novas pesquisas.

\section{Referenciais}

AZZI, Riolando. A formação histórica da matriz religiosa brasileira. In: Diálogo: Revista de Ensino Religioso, $\mathbf{n}^{0}$ 02. A matriz cultural religiosa brasileira. São Paulo: Paulinas, maio de 1996, p. $05-10$.

BRASIL. MEC. LDB 9.394/96. Belo Horizonte/MG: SEGRAC, 1997.

BRASIL. SECRETARIA DE EDUCAÇÃO FUNDAMENTAL. Parâmetros Curriculares Nacionais: introdução aos parâmetros nacionais. Brasília/DF: MEC/SEF, 1997.

BRASIL. SECRETARIA DE EDUCAÇÃO FUNDAMENTAL. Parâmetros Curriculares Nacionais: pluralidade cultural, orientação sexual. Brasília/DF: MEC/SEF, 1997.

CARON, Lurdes. Entre Conquistas e Concessões: uma experiência em educação religiosa escolar. São Leopoldo: Sinodal: IEPG, 1997a.

CARON, Lurdes (org.) e equipe do GRERE. O ensino religioso na nova LDB: histórico, exigências, documentário. $2^{\text {a }}$ ed. Petrópolis/RJ: Vozes, 1997b.

CELAM. Documento de Aparecida: Texto conclusivo da V Conferência Geral do Episcopado Latino-Americano e Caribe 13-31 de maio de 2007. CNBB: Brasília. Paulus: São Paulo. Paulinas: São Paulo. 2007.

CNBB. Relatórios dos Encontros Nacionais do Ensino Religioso 1974 a 1998 . Org. por CARON, Lurdes. Brasília/DF: Setor de Ensino Religioso, 2001.

DUSSEL, Henrique. El humanismo helénico. Buenos Aires: Editorial Universitária de Buenos Aires, p. IX-XXVII, 1975.

FONAPER. Parâmetros Curriculares Nacionais do Ensino Religioso. São Paulo/SP: Ave Maria, 1997.

FONAPER. Ensino Religioso capacitação para um novo milênio. Ensino Religioso e os seus Parâmetros Curriculares Nacionais. FONAPER: Curitiba. Caderno Pedagógico, 10, 2000.

FONAPER. Ensino Religioso capacitação para um novo milênio. Ensino Religioso na diversidade cultural-religiosa do Brasil. FONAPER: Curitiba. Caderno Pedagógico, 2, 2000 . 
FONAPER. Ensino Religioso capacitação para um novo milênio. Ensino Religioso nas tradições religiosas de matriz africana. FONAPER: Curitiba. Caderno Pedagógico, 7 , 2000 .

FONAPER. Ensino Religioso capacitação para um novo milênio. Ensino Religioso e o fenômeno religioso nas tradições religiosas de matriz indígena. FONAPER: Curitiba. Caderno Pedagógico, 5, 2000.

FONAPER. Ensino Religioso capacitação para um novo milênio. Ensino Religioso nas tradições religiosas de matriz ocidental. FONAPER: Curitiba. Caderno Pedagógico, 6, 2000 .

FONAPER. Ensino Religioso capacitação para um novo milênio. Ensino Religioso nas tradições religiosas de matriz oriental. FONAPER: Curitiba. Caderno Pedagógico, 8, 2000.

FREIRE, Paulo. Pedagogia do oprimido. 8. ed. Rio de Janeiro: Paz e Terra, 1980.

FREIRE, Paulo. Pedagogia da Autonomia: Saberes necessários à prática educativa. Ed.22, São Paulo: Paz e Terra, 2002.

GEERTZ, Clifford. A interpretação das culturas. Rio de Janeiro: Editora LTC, 1889.

JUNQUEIRA, Sérgio. O processo de escolarização do Ensino Religioso no Brasil. Petrópolis: Vozes, 2002.

ORTIZ, Renato. Cultura brasileira e identidade nacional e também, Currículo e cultura popular. São Paulo: Brasiliense, 2003.

SAVIANI, Demerval. Pedagogia histórico-crítica: primeiras aproximações. 2. ed. São Paulo: Cortez, 1991.d

Recebido: $12 / 03 / 2013$

Received: 03/12/2013

Aprovado: 04/07/2013

Approved: 07/04/2013 